\title{
National Inventory of Swiss Bryophytes (NISM)
}

\author{
Heike Hofmann \& Norbert Schnyder
}

\begin{abstract}
The NISM-database (GIVD ID EU-CH-004) contains bryophyte records from 1,237 relevés of $100 \mathrm{~m}^{2} .408$ of these relevés are located on a systematic grid which covers the whole of Switzerland and Liechtenstein (1 relevé). Further 430 plots have been placed randomly (429 in CH, 1 in LI) and 399 plots have been positioned arbitrarily into different habitat types (387 in CH, 12 in LI). On each plot all bryophyte species present were recorded. For each species on each plot the main substrate where the species was growing has been noted as well as their fertility. In total, the database contains 19,000 records from these relevés. At the moment we are just starting to analyse the data, but joint projects with other working groups are welcome.
\end{abstract}

Keywords: Switzerland.

GIVD Database ID: EU-CH-004

\section{National Inventory of Swiss Bryophytes (NISM)}

Scope: The NISM-database contains bryophyte records from 1,237 relevés of $100 \mathrm{~m}^{2} .408$ of these relevés are located on a systematic grid which covers the whole of Switzerland (407 relevés) and Liechtenstein (1). Further 430 plots have been placed randomly (429 in $\mathrm{CH}, 1$ in LI) and 399 plots have been positioned arbitrarily into different habitat types (387 in $\mathrm{CH}, 12$ in LI). On each plot all bryophyte species present were recorded. In total the database contains 19,000 records from these relevés.

Status: completed and continuing Period: 1984-2006

Database manager(s): Heike Hofmann (heike.hofmann@systbot.uzh.ch); Norbert Schnyder (norbert.schnyder@systbot.uzh.ch)

Owner: Mapping committee of the National Inventory of Swiss Bryophytes

Web address: http://www.nism.uzh.ch/

Availability: according to a specific agreement

Database format(s): Oracle

Online upload: no

Online search: yes

Publication: Urmi, E., Schnyder, N., \& Geissler, P. 1990. A new method in floristic mapping as applied to an inventory of Swiss bryophytes. In: Bohn, U. \& Neuhäusel, R. (eds.), Vegetation and flora of temperate zones, SPB Academic Publishing, The Hague, The Netherlands, 21-32

Plot type(s): normal plots

Plot-size range: $100-100 \mathrm{~m}^{2}$

Non-overlapping plots: 1,237

Total plot observations: 1,237

Estimate of existing plots: [NA]

Completeness: [NA]

Countries: $\mathrm{CH}$ : $99.0 \%$; LI: $1.0 \%$

Forest: [NA] — Non-forest: [NA]

Guilds: bryophytes (terricolous or aquatic): $100 \%$

Environmental data: altitude: $100 \%$

Performance measure(s): presence/absence only: $100 \%$

Geographic localisation: GPS coordinates (precision $25 \mathrm{~m}$ or less): 5\%; point coordinates less precise than GPS, up to $1 \mathrm{~km}$ : $95 \%$

Sampling periods: $1980-1989: 45.6 \% ; 1990-1999: 32.4 \% ; 2000-2009: 22.0 \%$

Information as of 2012-07-12; further details and future updates available from http://www.givd.info/ID/EU-CH-004

Heike Hofmann* (heike.hofmann@systbot.uzh.ch), Norbert Schnyder (norbert.schnyder@ systbot.uzh.ch)

Institute of Systematic Botany, University of Zurich, Zollikerstr. 107, 8008 Zurich, SWITZERLAND

*Corresponding author 